Article

\title{
Transcriptomic and ChIP-seq Integrative Analysis Reveals Important Roles of Epigenetically Regulated lncRNAs in Placental Development in Meishan Pigs
}

\author{
Dadong Deng, Xihong Tan, Kun Han, Ruimin Ren, Jianhua Cao and Mei Yu* \\ Key Lab of Agricultural Animal Genetics, Breeding and Reproduction of Ministry of Education, \\ College of Animal Science and Technology, Huazhong Agricultural University, Wuhan 430070, China; \\ dadong_deng@163.com (D.D.); xihongTan_920@163.com (X.T.); hankun19910110@163.com (K.H.); \\ ruimin.ren@webmail.hzau.edu.cn (R.R.); jhcao@mail.hzau.edu.cn (J.C.) \\ * Correspondence: yumei@mail.hzau.edu.cn
}

Received: 2 March 2020; Accepted: 2 April 2020; Published: 6 April 2020

\begin{abstract}
The development of the placental fold, which increases the maternal-fetal interacting surface area, is of primary importance for the growth of the fetus throughout the whole pregnancy. However, the mechanisms involved remain to be fully elucidated. Increasing evidence has revealed that long non-coding RNAs (lncRNAs) are a new class of RNAs with regulatory functions and could be epigenetically regulated by histone modifications. In this study, 141 lncRNAs (including 73 up-regulated and 68 down-regulated lncRNAs) were identified to be differentially expressed in the placentas of pigs during the establishment and expanding stages of placental fold development. The differentially expressed lncRNAs and genes (DElncRNA-DEgene) co-expression network analysis revealed that these differentially expressed lncRNAs (DElncRNAs) were mainly enriched in pathways of cell adhesion, cytoskeleton organization, epithelial cell differentiation and angiogenesis, indicating that the DElncRNAs are related to the major events that occur during placental fold development. In addition, we integrated the RNA-seq (RNA sequencing) data with the ChIP-seq (chromatin immunoprecipitation sequencing) data of $\mathrm{H} 3 \mathrm{~K} 4 \mathrm{me} / \mathrm{H} 3 \mathrm{~K} 27 \mathrm{ac}$ produced from the placental samples of pigs from the two stages (gestational days 50 and 95). The analysis revealed that the changes in H3K4me3 and/or H3K27ac levels were significantly associated with the changes in the expression levels of 37 DElncRNAs. Furthermore, several H3K4me3/H3K27ac-lncRNAs were characterized to be significantly correlated with genes functionally related to placental development. Thus, this study provides new insights into understanding the mechanisms for the placental development of pigs.
\end{abstract}

Keywords: lncRNA; histone modifications; placental development; pig

\section{Introduction}

The placenta is an organ that provides nutrients and oxygen to the developing fetus during pregnancy. The pig has an epitheliochorial type of placenta, in which the trophoblast epithelial layer interdigitates with the maternal endometrial epithelial layer to form the folded bilayer [1]. Around gestational day 50 (the gestational length is about 114 days in pigs), the placental fold development reaches a temporary steady state. Thereafter, as gestation progresses, the placental fold increases in depth or complexity to further expand the exchange surface area [2-5]. Therefore, the placental fold development is a critical contributor to maintaining the function of porcine placentas. In pigs, fetal loss and depression in piglet birth weight are primary factors associated with reproductive performance and were demonstrated to be mainly caused by placental dysfunction [6-9]. Although many genes and factors have been reported to be involved in the development of the porcine placental fold $[3,4,10,11]$, the mechanism for porcine placental development remains to be fully elucidated. 
Long non-coding RNAs (lncRNAs) are known to be larger than $200 \mathrm{nt}$ with little or no coding potential $[12,13]$. They play a diverse role in biological processes, including transcriptional and post-transcriptional regulation, as well as chromatin remodeling [14-19]. In humans, a large number of IncRNAs were identified throughout the genome in term placenta [20]. Several lncRNAs, such as H19 imprinted maternally expressed transcript (H19), X-inactive specific transcript (Xist) and SPRY4 intronic transcript 1 (SPRY4-IT1), were also characterized to be associated with trophoblast development and placental disease [21-24]. In addition, Bischoff et al. revealed the differences in Xist isoform expression between the commercial swine populations and the Meishan placentas [25]. These findings indicate a significant role of the IncRNA in the regulation of the placental development and function.

Histone modifications, such as methylation and acetylation, have been demonstrated to be the important epigenetic modifications that have an important impact on gene transcription [26-28]. Recent studies revealed that lncRNAs could be epigenetically regulated in a broad range of biological processes, including Alzheimer's disease (AD), embryonic stem (ES) cells and placental development [22,29-31]. Previously, by using ChIP-seq (chromatin immunoprecipitation sequencing) and RNA-seq (RNA sequencing) approaches, we identified the genome-wide profiles of H3K4me3 and H3K27ac in porcine placentas at gestational days 50 (establishment stage of the placental fold) and 95 (expanding stage of the placental fold). In this study, from the perspective of IncRNA genes other than protein-coding genes, we re-analyzed the data sets in an effort to (1) identify the differentially expressed lncRNAs (DElncRNAs) in porcine placentas during the two developmental stages; (2) characterize the DElncRNAs that may be epigenetically regulated; (3) investigate the H3K4me3/H3K27ac-lncRNA-gene pathways that may be associated with placental development in pigs.

\section{Materials and Methods}

\subsection{Samples and RNA Preparation}

All procedures for the collection of samples were performed according to protocols approved by the biological study animal care and use committee from The Scientific Ethic Committee of Huazhong Agricultural University, Hubei province (HZAUSW-2016-015). Chinese Meishan gilts were raised in the pig farm of Huazhong Agricultural University (Wuhan, China) and were naturally mated with one Meishan boar at the onset of estrus (day $=0$ ) and again $24 \mathrm{~h}$ later. The gilts were euthanized on gestational day 50 or 95 ( $n=3-5$ gilts/gestational day). The placenta (chorioallantoic tissue) was collected and snap-frozen in liquid nitrogen as previously described [11]. The total RNA from each placenta was extracted by using Trizol reagent (Invitrogen, Carlsbad, CA, USA). The quality and quantity of these RNA samples were determined by an Agilent 2100 Bioanalyzer (Agilent Technologies, Santa Clara, CA, USA).

\subsection{RNA-seq Analysis}

In this study, a total of eight libraries ( 3 and 5 placentas from gestational days 50 and 95, respectively) were constructed for RNA sequencing using an Illumina HiSeq X Ten sequencer (Novogene, Beijing, China). Paired end reads of $2 \times 150$ base pairs from each sample were generated. Previously, we reported the protein-coding gene expression data based on the RNA-seq data generated from 10 other placental samples of Meishan gilts ( 6 and 4 placentas from gestational days 50 and 95, respectively) [11]. In the present study, the 2 RNA-seq data sets were combined for further analyses with the aim of identifying the IncRNAs and their co-expressed genes. Thus, the RNA-seq data generated from 18 randomly selected placental samples ( 9 and 9 placentas from gestational days 50 and 95 , respectively) were used in the study and the data were deposited into the NCBI (national center for biotechnology information) Sequence Read Archive database (SRP251127). The reads containing an adapter or poly-N and reads of low quality were removed from the raw reads to generate the clean reads for further analyses. The clean reads were mapped with HISAT2 [32] to the porcine genome sequence (Sscrofa 11.1). The mapped reads of each sample were assembled by both Cufflinks [33] and StringTie [34]. Information about the 
number and quality of the RNA-seq data is listed in Table S1. Read counts and TPM (transcripts per kilobase of exon model per million mapped reads) for each gene and lncRNA from each sample were calculated using StringTie [34,35].

\subsection{LncRNA Detection}

To identify lncRNAs in porcine placenta, we designed a lncRNA analysis pipeline: (1) we compared our porcine placental RNA-seq-assembled transcriptome with Sscrofa 11.1 genome annotation and kept the novel transcripts located in intergenic, intron and anti-sense regions; (2) we removed the transcripts whose length was less than 200 nucleotides or whose number of exons was less than 2 as well as those lowly expressed transcripts (less than 2 individuals with TPM $>1$ in the transcript) (3) we assessed the protein-coding potential of the transcripts and distinguished the protein-coding and non-coding transcripts by using coding potential calculator (CPC) [36] and coding potential assessment tool (CPAT) [37]. Transcripts without coding potential were considered to be the candidate lncRNAs.

\subsection{Differential Expression Analysis}

The read counts of each lncRNA and gene were used for differential expression analysis by using edgeR [38]. Genes or lncRNAs with an adjust $p$-value (Benjamini-Hochberg methods) $<0.05$ and fold-change $>2$ were assigned as being differentially expressed.

\subsection{IncRNA-Gene Co-Expression Analysis}

The Pearson correlation coefficients (PCC) between the lncRNAs and genes were calculated with $\log 2$ transformation of the raw TPM. The co-expressed genes of the lncRNAs were identified with the PCC $>0.9$ and $p<0.0001$.

\subsection{ChIP-seq Analysis}

Previously, we published the ChIP-seq data of H3K4me3 and H3K27ac [11]. The data were generated from 5 porcine placentas ( 3 and 2 placentas from gestational days 50 and 95, respectively). In this study, we re-analyzed the ChIP-seq data using the same pipeline. Peaks that are within the $3 \mathrm{~kb}$ region from the TSS (transcription start sites) of the differentially expressed lncRNAs and that increased or decreased more than 2-fold between gestational days 50 and 95 were defined as the significant differential modifications.

\subsection{Gene Ontology (GO) Enrichment Analysis}

The co-expressed genes of the differentially expressed lncRNA were used for enrichment analysis. The enrichment of the specific gene ontology (GO) biological processes was analyzed using the DAVID Web-based tool (https://david.ncifcrf.gov).

\subsection{Quantitative Real-Time PCR and ChIP-qPCR}

Quantitative real-time PCR (qRT-PCR) and ChIP Quantitative PCR (ChIP-qPCR) were carried out for validating the RNA-seq and ChIP-seq data, respectively. Reverse transcription was performed using a PrimeScript RT Reagent Kit with a gDNA Eraser (Takara Bio Inc., Dalian, China). The specific primers of genes and lncRNAs were designed using the software of primer BLAST from NCBI (Table S1). The glyceraldehyde-3-phosphate dehydrogenase (GAPDH) gene was used as a control. The genes and IncRNAs' expression levels of different samples were compared by the $2^{-\Delta \Delta C T}$ method [39]. Primers for ChIP-qPCR were designed within the significant differentially modified regions determined by the ChIP-seq assay (Table S1). The input DNA sample was used as the negative control. The qRT-PCR and ChIP-qPCR were performed using standard SYBR Premix Ex TaqII (Tli RNaseH Plus; Takara Bio) in a Bio-Rad CFX384 Touch Real-Time PCR Detection System (Bio-Rad Laboratories, Inc., Hercules, CA, 
USA). The comparison between gestational days 50 and 95 was made using Student's $t$-test. $p<0.05$ was considered statistically significant.

\section{Results}

\subsection{Identification of Differentially Expressed lncRNAs in Porcine Placentas}

In total, 690 putative lncRNAs were identified to be expressed in porcine placentas (chorioallantoic tissues) on gestational days 50 and 95 . Among these, 479 lncRNAs were transcribed from intergenic regions, 206 lncRNAs were transcribed as overlapping with and in the antisense orientation to a reference and five lncRNAs were transcripts falling entirely within a reference intron (Table S2). In addition, a total of 141 lncRNAs were found to be differentially expressed in placentas between gestational days 50 and 95 (adjusted $p$-value $<0.05$; fold change $>2$ ), including 73 up-regulated and 68 down-regulated lncRNAs on gestational days 95 (Figure 1 and Table S3).

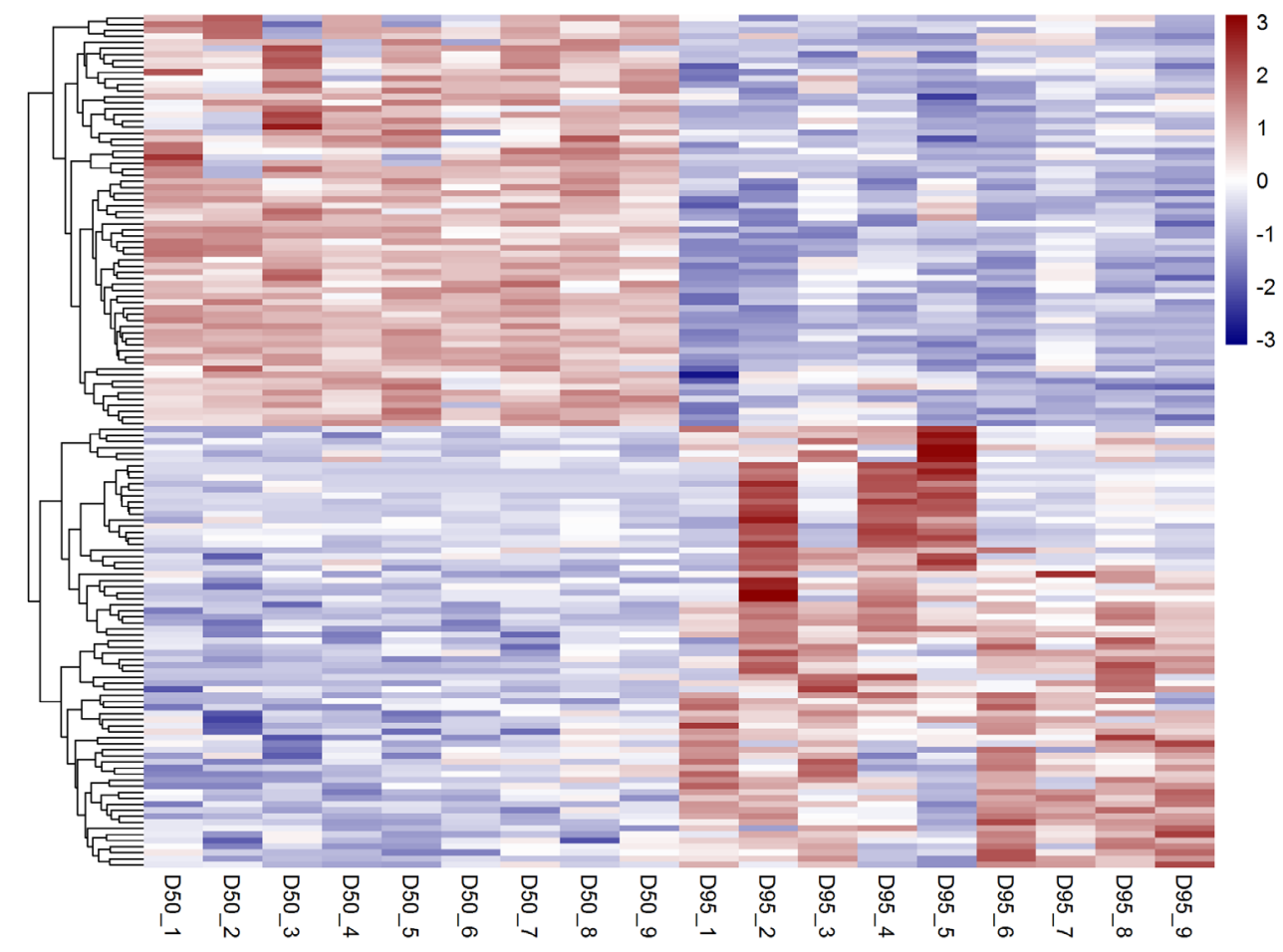

Figure 1. Expression profiles of the differentially expressed long non-coding RNAs (lncRNAs) in the porcine placentas on gestational days 50 and 95 by RNA-seq (adjusted $p$-value $<0.05$ ). D50, gestational day 50; D95, gestational day 95.

\subsection{Analysis of the Potential Function of the Differentially Expressed LncRNAs}

To understand the potential function of the differentially expressed lncRNAs (DElncRNAs), the differentially expressed genes (DEgenes) were detected using the same data set generated from the 18 porcine placental samples. A total of 2208 genes were found to be differentially expressed between gestational days 50 and 95 (including 1689 up-regulated and 519 down-regulated genes, adjusted $p$-value $<0.05$, fold change $>2$, Table S3). Then, we investigated the co-expression relationships between the DElncRNAs and DEgenes using Pearson's correlation analysis. In total, 1002 significantly co-expressed lncRNA-gene pairs $\left(p<0.0001, \mathrm{PCC}^{2}>0.8\right)$ were identified, in which 72 DElncRNAs (including 37 up-regulated and 35 down-regulated lncRNAs, respectively) and 569 DEgenes were involved (Table S4). Subsequently, gene ontology (GO) analysis was conducted for the 569 co-expressed DEgenes by using DAVID online tools (Figure 2 and Table S5). The most significantly overrepresented 
terms for the co-expressed DEgenes of the down-regulated lncRNAs were involved in cytoskeleton organization, the regulation of Rho protein signal transduction, cell adhesion, actin cytoskeleton reorganization and the regulation of cell shape, whereas the most significantly overrepresented terms for the co-expressed DEgenes of the up-regulated lncRNAs were related to angiogenesis, signal transduction, epithelial cell differentiation, vasculogenesis, regulation of cell shape, the unsaturated fatty acid biosynthetic process and the positive regulation of GTPase activity.

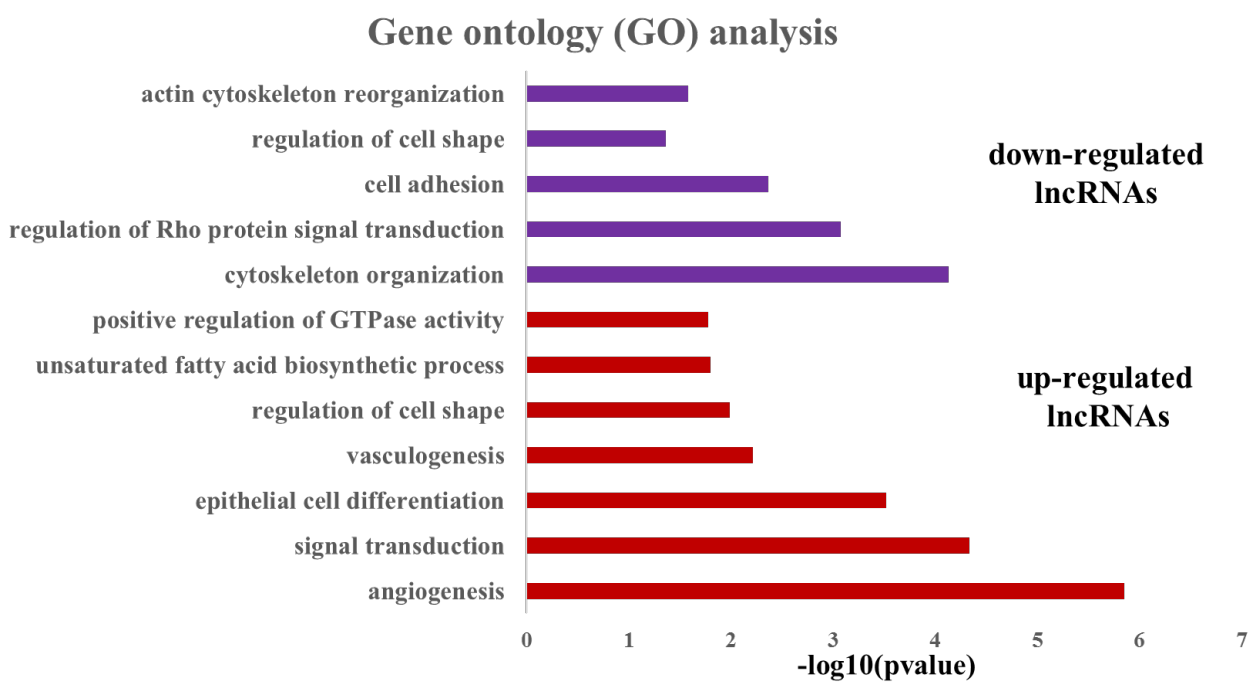

Figure 2. Gene ontology analysis of the co-expressed genes with the differentially expressed lncRNAs (DElncRNAs).

\subsection{Investigation of the Role of H3K4me3 and H3K27me3 Modifications in Regulation of the IncRNA} Expression in Porcine Placentas

Previously, we reported the genome-wide maps of H3K4me3 and H3K27ac in placentas from gestational days 50 and 95 in pigs [11]. In the current study, the data were re-analyzed to identify those DElncRNAs that may be epigenetically regulated by the H3K4me3 and H3K27ac modifications. The significant differential modifications between the two stages within the $3 \mathrm{~kb}$ region from the TSS of the 37 DElncRNAs were detected, including 32 H3K4me3 (increased signals: 32; decreased signals: 0) and 16 H3K27ac (increased signals: 7; decreased signals: 9) peaks (Table S6), respectively. Of these 37 DElncRNAs, four DElncRNAs had both H3K4me3- and H3K27ac-increased regions, 22 DElncRNAs had H3K4me3-increased regions, three DElncRNAs had H3K27ac-increased regions and eight DElncRNAs had H3K27ac-decreased regions (Table S6). We next confirmed that the expression levels of 13 DElncRNAs and the enrichments of H3K4me3 and/or H3K27ac in the 13 DElncRNAs (including seven lncRNAs enriched with H3k4me3, four lncRNAs enriched with H3k27ac and two lncRNAs enriched with both $\mathrm{H} 3 \mathrm{~K} 4 \mathrm{me} 3$ and H3K27ac modifications, respectively) were consistent with the results from the RNA-seq and ChIP-seq data (Figure 3A-C), respectively. Furthermore, the expression levels of the 37 DElncRNAs were quantified by using the RNA-seq data: the results showed that the increased levels of the 29 up-regulated lncRNAs were significantly associated with the increased enrichments of $\mathrm{H} 3 \mathrm{~K} 4 \mathrm{me} 3$ and/or H3K27ac, while the decreased levels of the eight down-regulated lncRNAs were significantly associated with the decreased enrichment of H3K27ac (Figure 3D). 


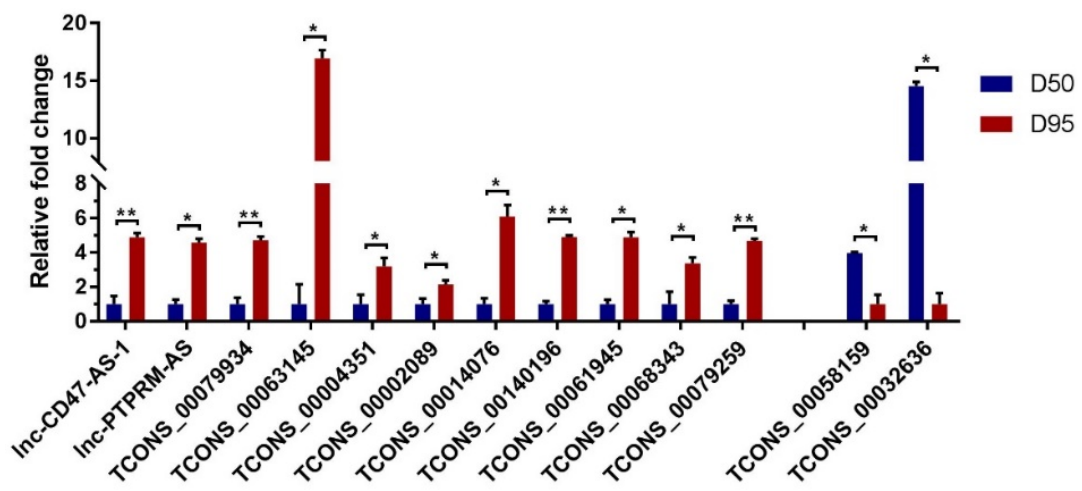

(a)

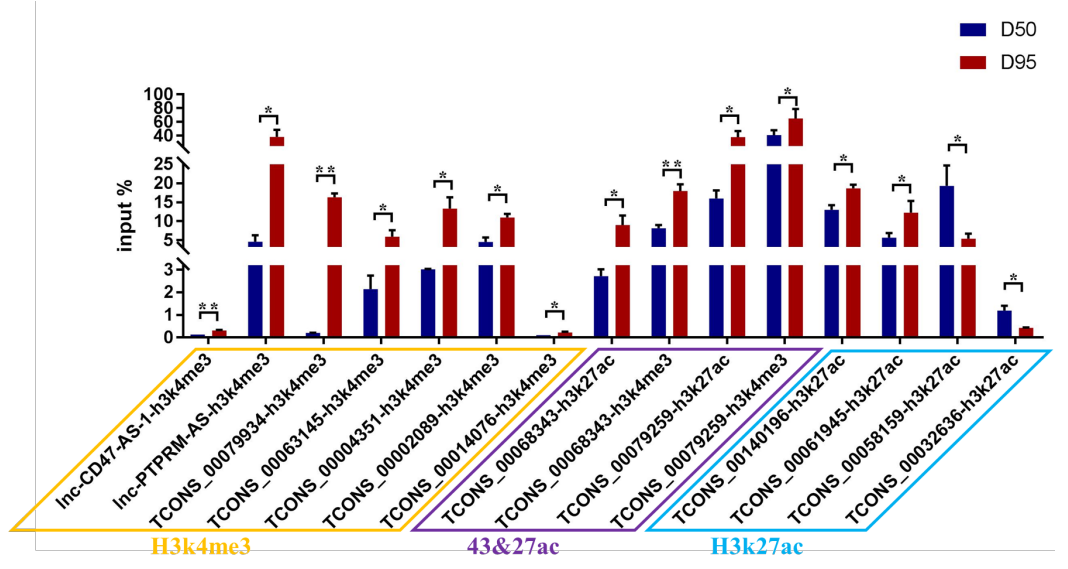

(b)

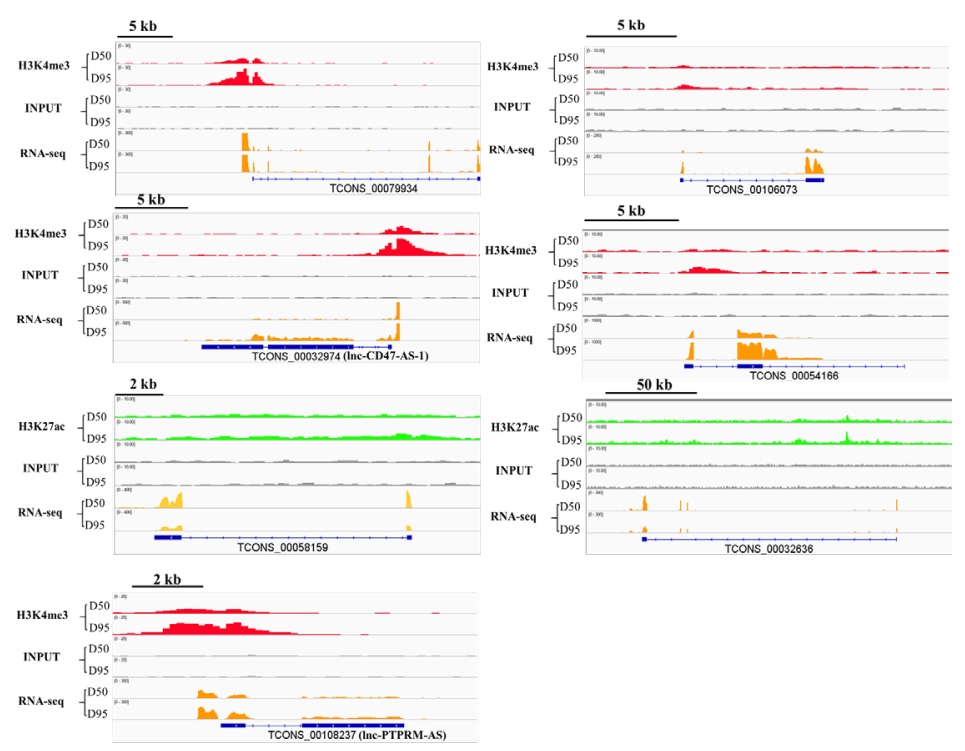

(c)

Figure 3. Cont. 


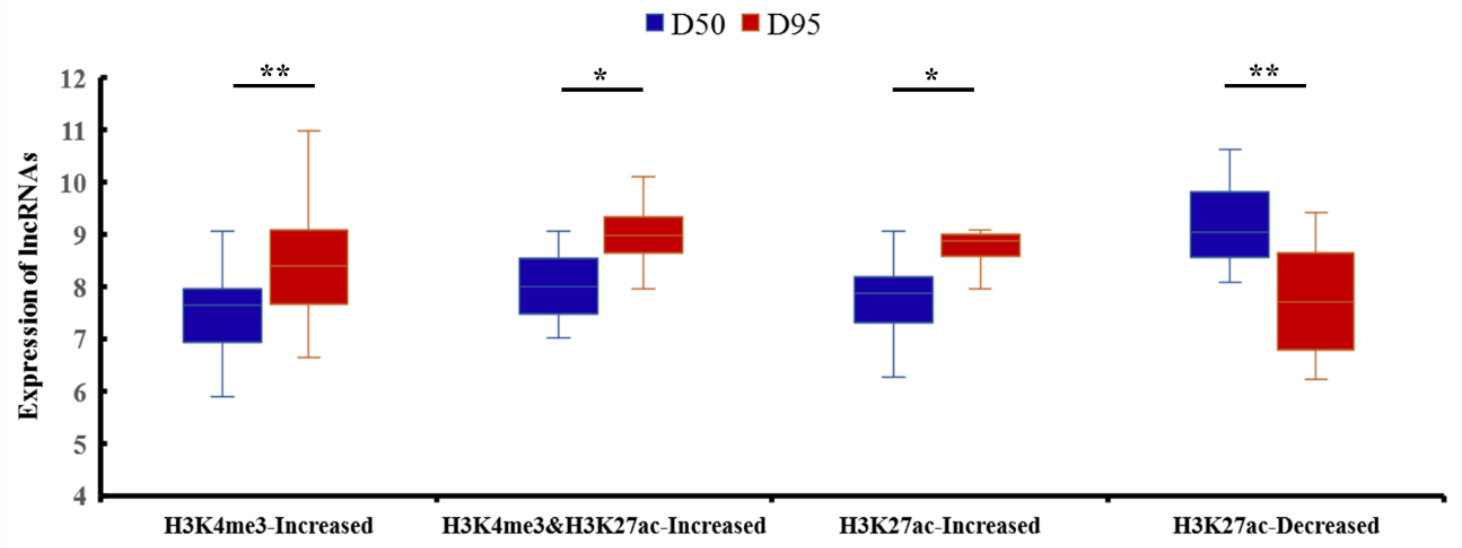

(d)

Figure 3. DElncRNAs were regulated by the H3K4me3 and H3K27ac modifications. (A) Quantitative real-time PCR (qRT-PCR) validation of the differentially expressed lncRNAs in porcine placenta on gestational days 50 and 95. (B) ChIP Quantitative PCR (ChIP-qPCR) validation of the H3K4me3 and H3K27ac modifications of the differentially expressed lncRNAs in porcine placenta on gestational days 50 and 95. (C) IGV (Integrative Genome Viewer) views of the H3K4me3 and/or H3K27ac modification patterns. (D) Box plots of the expression value of the lncRNAs that were modified by H3K4me3 and/or H3K27ac. Data are represented as mean $+\mathrm{SEM}, \mathrm{n}=3 .{ }^{*} p<0.05 ;{ }^{* *} p<0.01$. D50, gestational day 50; D95, gestational day 95.

3.4. Validation of the Expression Pattern of DEgenes Co-Expressed with the H3K4me3- and/or H3K27acModified DElncRNAs

Of the 13 DElncRNAs whose expression levels were confirmed to be significantly associated with the enrichments of H3K4me3 and/or H3K27ac in placentas during gestational days 50 and 95 in pigs, seven DElncRNAs (lncRNAs TCONS_00079934, TCONS_00106073, Inc-PTPRM-AS, TCONS_00054166, Inc-CD47-AS-1, TCONS_00058159 and TCONS_00032636) were found to have a strong co-expression relationship with 12 genes (Figure 4A). Then, the expression pattern of the genes co-expressed with these DElncRNAs was validated using qRT-PCR. As shown in Figure 4B, nine genes were confirmed to be up-regulated on gestational day 95, namely ITGA9 (integrin subunit alpha 9), PIK3CG (phosphatidylinositol 4,5-bisphosphate 3-kinase catalytic), TGFB2 (transforming growth factor beta 2), PTPRB (protein tyrosine phosphatase, receptor type B), CD8A (T-cell surface glycoprotein CD8 alpha chain), CD47 (leukocyte surface antigen CD47), CAV1 (caveolin 1), VEGFR-2 (kinase insert domain receptor), and $A K T 3$ (AKT serine/threonine kinase 3), while three genes were validated to be down-regulated on gestational day 95, namely CTSB (cathepsin B), BCR (BCR activator of RhoGEF and GTPase), and TIAM2 (T-cell lymphoma invasion and metastasis 2). 

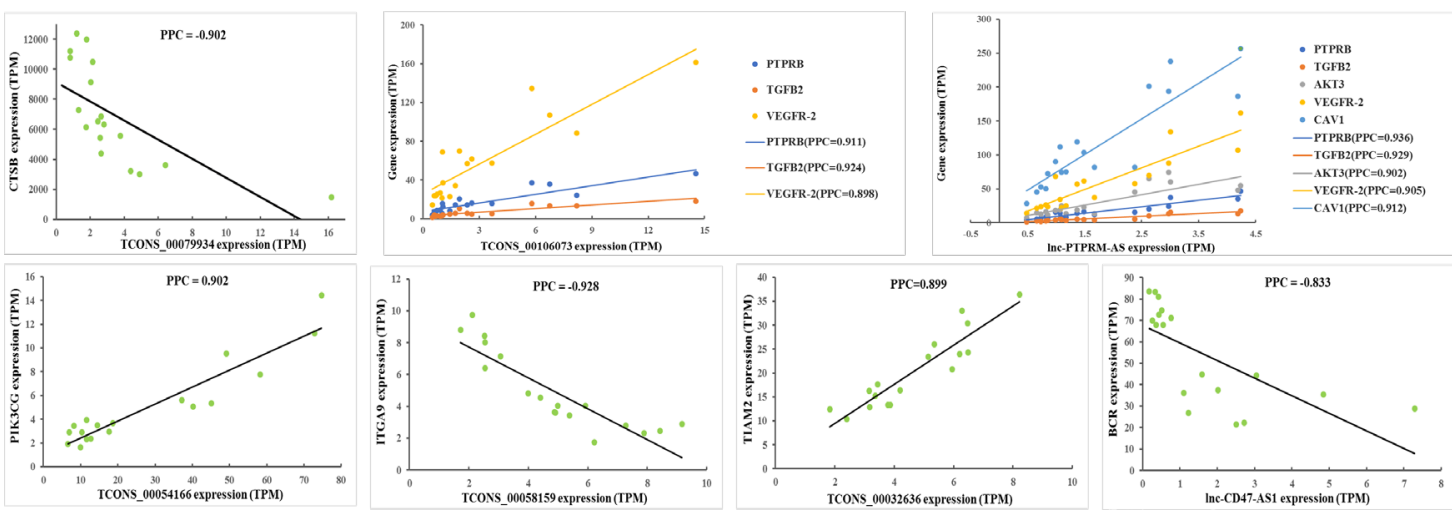

(a)

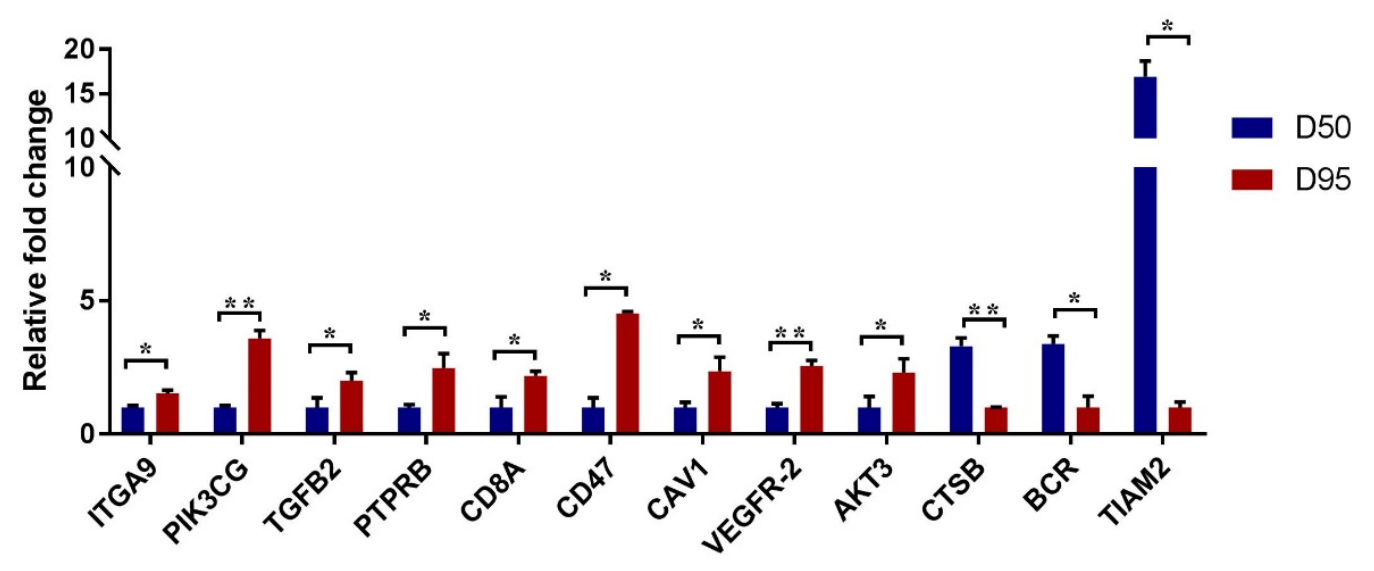

(b)

Figure 4. Validation of the expression pattern of the DEgenes co-expressed with the H3K4me3and/or H3K27ac-modified DElncRNAs. (A). A scatterplot of the DElncRNAs and co-expression genes' expression levels in individual placental samples determined by RNA-Seq. (B). Quantitative RT-PCR validation of the DEgenes co-expressed with the DElncRNAs. PCC, Pearson correlation coefficient; data are represented as mean $+\mathrm{SEM}, \mathrm{n}=3 .{ }^{*} p<0.05{ }^{*} p<0.01$.

\section{Discussion}

In this study, the lncRNAs that were differentially expressed (DElncRNAs) in porcine placentas from the two crucial placental fold developmental stages were detected. The DEgenes co-expressed with these DElncRNAs were found to be enriched in the pathways related to angiogenesis, cell adhesion, cytoskeleton organization and epithelial cell differentiation. In addition, the DElncRNAs that were marked by H3K4me3 and/or H3K27ac were identified and the expression of these DElncRNAs was detected to be significantly correlated to the changes in the level of H3K4me3 and/or H3K27ac. Furthermore, the H3K4me3/H3K27ac-lncRNA-gene pathways were validated in the placentas of pigs from the two crucial placental fold developmental stages.

As gestation progresses in pigs, the demand of the fetuses for nutrient uptake increases rapidly, thus the placental fold develops further for increasing the maternal-fetal exchange surface area and expanding the maternal and fetal vascular network [2,4,7,40]. A number of genes and miRNAs, such as heparanase (HPSE), hypoxia inducible factor 1a (HIF1A), vascular endothelial growth factor A (VEGFA) and miR-29a, were reported to be functionally related to placental development $[3,10,41-43]$. 
Recently, RNA-seq data analysis was performed on the placentas of Landrace $\times$ Yorkshire gilts on gestational days 60 and 90, as well as the farrowing day. The mRNAs and lncRNAs that were responsible for the bile acid metabolism in placentas were identified [44]. We reported here the lncRNAs that were differentially expressed in the placentas (chorioallantoic tissues) of Meishan gilts from the two crucial placental fold developmental stages: gestational days 50 (establishment stage of placental fold) and 95 (expanding stage of placental fold) and the differential expression of the DElncRNAs was validated by using qRT-PCR. Our finding is in agreement with the previous report demonstrating the role of lncRNAs in regulating the gene expression in the placentas of pigs [44]. On the other hand, in addition to vasculature development, it has been documented that the placental trophoblast cells undergo differentiation and change in cell shape during the development of the placental fold in pigs [3,45-48]. Our DElncRNA-DEgene co-expression network analysis revealed that these DElncRNAs were mainly enriched in pathways of cell adhesion, cytoskeleton organization, epithelial cell differentiation and angiogenesis, indicating that the DElncRNAs are related to the major events that occur during the placental fold development $[4,11,45,49,50]$. These findings suggest the important role of these DElncRNAs in the development of the placental fold.

There is growing evidence that DNA methylation and histone modification can impact lncRNA expression by altering the chromatin structure [29,51-53]. Therefore, we performed an integrative analysis of the lncRNA data and our previously reported ChIP-seq data of H3K4me3 and H3K27ac modifications derived from the placentas of pigs [11]. A total of 37 DElncRNAs (including 29 up-regulated lncRNAs and 8 down-regulated lncRNAs on gestational day 95) were identified to contain H3K4me3 and/or H3K27ac marks within a $3 \mathrm{~kb}$ region from the TSS. H3K4me3 and H3K27ac are two of the active chromatin marks that have been illustrated to be associated with active transcription [54-58]. As expected, we found that those up-regulated lncRNAs were associated with the increased levels of $\mathrm{H} 3 \mathrm{~K} 4 \mathrm{me} 3$ and/or H3K27ac, while those down-regulated lncRNAs were associated with the decreased H3K27ac levels. The findings indicate that the expression of the lncRNAs in the placentas of pigs were at least in part epigenetically regulated by the two histone modifications. Furthermore, we validated that five lncRNAs with increased H3K4me3 and upregulation in expression were significantly co-expressed with 10 DEgenes including CTSB, CD8A, PTPRB, TGFB2, VEGFR-2, AKT3, CAV1, PIK3CG, BCR and CD47, while two lncRNAs with decreased H3K27ac and downregulation in expression were significantly co-expressed with two DEgenes: ITGA9 and TIAM2. CTSB is a lysosomal cysteine protease that can degrade the extracellular matrix (ECM) and was confirmed to be expressed in the chorionic epithelium of the placenta in pigs $[59,60]$. CD8A encodes the alpha chain of CD8, which is a co-receptor for the MHC class I molecule peptide complex and plays an essential role in the immune response [61]. Five of the DEgenes, PTPRB, TGFB2, AKT3, PIK3CG and ITGA9, are involved in a wide variety of biological processes such as epithelium morphogenesis, angiogenesis and immune homeostasis [62-66]. VEGFR-2 is one of the VEGF transmembrane tyrosine kinase receptors. It has been reported that VEGFR-2 functions in the regulation of VEGF by interaction with $C D 47$, thus the two genes play key roles in angiogenesis and vascular permeability [67-70]. The integral membrane protein encoded by $C A V 1$ is the main component of the caveolar membranes and acts with diverse functions in cells, such as cell differentiation and movement [71-73]. BCR plays a role in regulating small GTP-binding proteins, such as CDC42 (cell division cycle 42). CDC42 was detected to be expressed in the placenta of pigs and functions in epithelial tissue morphogenesis [74,75]. TIAM2 has been characterized to promote the cell proliferation and invasion [76,77].

Overall, we validated that changes in the expression levels of seven lncRNAs were significantly associated with changes in H3K4me3 and/or H3K27ac levels. In addition, 12 genes which play roles in epithelial cell differentiation, angiogenesis, cell adhesion and cytoskeleton organization were validated to be co-expressed with the seven lncRNAs during the placental development of pigs. Of these lncRNAs, Inc-CD47-AS-1 is overlapped with CD47 on the opposite stand and Lnc-TCONS_00079934 is localized near the CD8A gene. These two lncRNAs may regulate the two genes by recruiting regulatory complexes through RNA-protein interactions [18,78,79]. In addition, five lncRNAs (TCONS_00079934, 
TCONS_00106073,TCONS_00054166,TCONS_00058159 and TCONS_00032636) are intergenic lncRNAs and $\operatorname{lnc}-P T P R M-A S$ is an antisense lncRNA (Table S6). These six lncRNAs and their corresponding co-expressed genes are located on the different chromosomes, suggesting that these lncRNAs may regulate gene expression in trans through the mechanism of proximity transfer [79-81]. Thus, we speculated that the epigenetic transcriptional marks, H3K4me3 and H3K27ac, may have an impact on the expression of the lncRNAs and these lncRNAs may act in cis or in trans to affect the transcription of the co-expressed genes during the placental development of pigs (Figure 5).

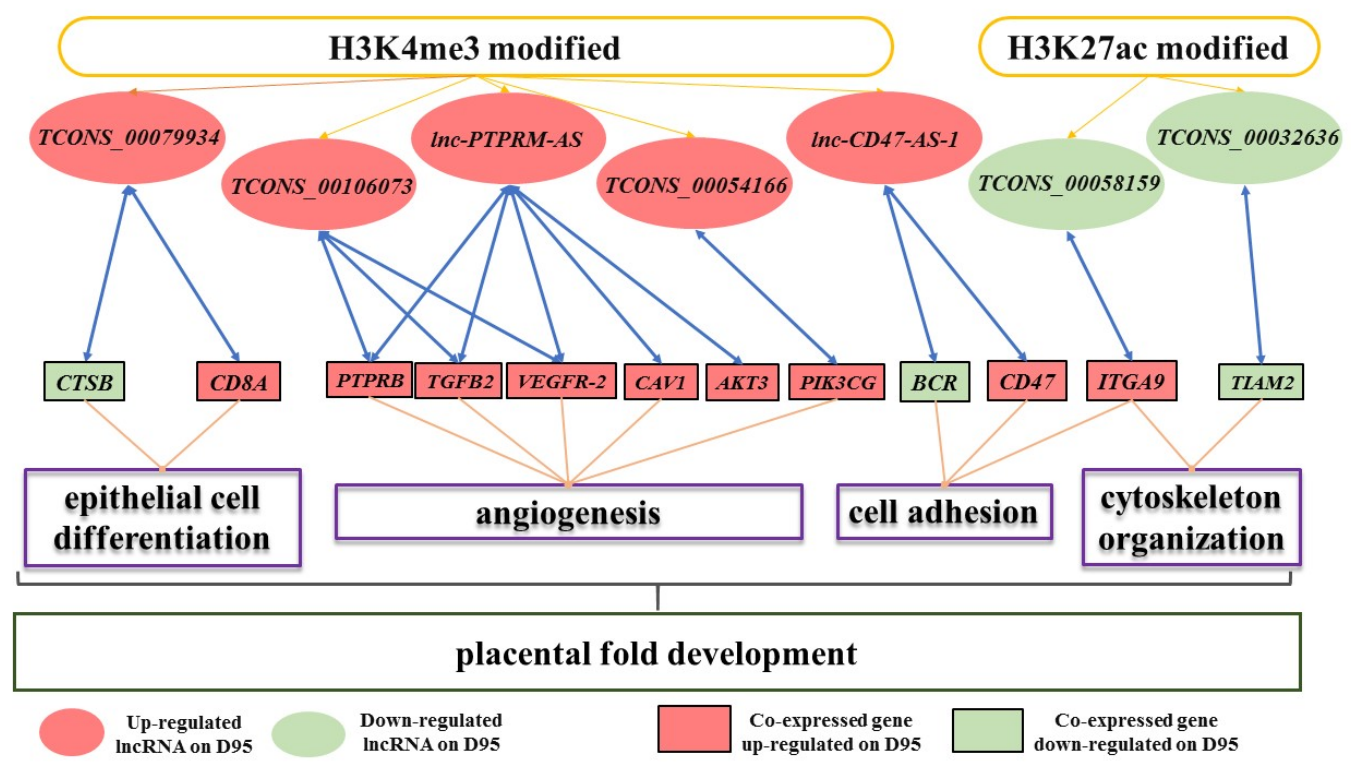

Figure 5. Schematic illustration of the potential roles of H3K4me3/H3K27ac-lncRNA-gene pathways on porcine placental development.

In conclusion, this study identified the lncRNAs that are differentially expressed in the placentas of pigs obtained from two crucial placental fold developmental stages. In addition, we characterized DElncRNAs whose expression changes are correlated with altered levels of H3K4me3 and/or H3K27ac. Furthermore, H3K4me3/H3K27ac-lncRNA-gene pathways are suggested to play important roles in the placental fold development of pigs.

Supplementary Materials: The following are available online at http://www.mdpi.com/2073-4425/11/4/397/s1, Table S1: Information of the RNA-Seq data and primers, Table S2: Information of the identified lncRNAs, Table S3: The differentially expressed lncRNAs and genes, Table S4: The significantly co-expressed lncRNA-gene pairs, Table S5: Gene ontology analysis data, Table S6: Information of H3K4me3/H3K27ac-lncRNAs.

Author Contributions: M.Y. conceived and designed the experiments; D.D., X.T., K.H. and R.R. performed the experiments; D.D., K.H., J.C. and M.Y. analyzed the data; D.D. and M.Y. wrote and revised the paper. All authors have read and agreed to the published version of the manuscript.

Funding: This research was funded by the Natural Science Foundation of China $(31730089,31572370)$, Natural Science Foundation of Hubei Province (Grant\# 2018CFA015) and Fundamental Research Funds for the Central Universities (Program No. 2662018PY037).

Conflicts of Interest: The authors declare no conflict of interest.

\section{References}

1. Leiser, R.; Pfarrer, C.; Abd-Elnaeim, M.; Dantzer, V. Feto-maternal anchorage in epitheliochorial and endotheliochorial placental types studied by histology and microvascular corrosion casts. Placenta 1998, 19, 21-39. [CrossRef] 
2. Vallet, J.L.; McNeel, A.K.; Johnson, G.; Bazer, F.W. TRIENNIAL REPRODUCTION SYMPOSIUM: Limitations in uterine and conceptus physiology that lead to fetal losses. J. Anim. Sci. 2013, 91, 3030-3040. [CrossRef] [PubMed]

3. Hong, L.J.; Hou, C.Y.; Li, X.P.; Li, C.C.; Zhao, S.H.; Yu, M. Expression of Heparanase Is Associated with Breed-Specific Morphological Characters of Placental Folded Bilayer between Yorkshire and Meishan Pigs. Biol. Reprod. 2014, 90, 1-9. [CrossRef] [PubMed]

4. Seo, H.; Li, X.; Wu, G.; Bazer, F.W.; Burghardt, R.C.; Bayless, K.J.; Johnson, G.A. Mechanotransduction drives morphogenesis to develop folding during placental development in pigs. Placenta 2020, 90, 62-70. [CrossRef] [PubMed]

5. Bazer, F.W.; Johnson, G.A. Pig blastocyst-uterine interactions. Differentiation 2014, 87, 52-65. [CrossRef]

6. Dantzer, V. Electron microscopy of the initial stages of placentation in the pig. Anat. Embryol. 1985, 172, 281-293. [CrossRef]

7. Vallet, J.L.; Freking, B.A. Differences in placental structure during gestation associated with large and small pig fetuses. J. Anim. Sci. 2007, 85, 3267-3275. [CrossRef]

8. Vallet, J.; Miles, J. Development of the pig placenta. Soc. Reprod. Fertil. Suppl. 2009, 66, 265-279.

9. Bidarimath, M.; Tayade, C. Pregnancy and spontaneous fetal loss: A pig perspective. Mol. Reprod. Dev. 2017, 84, 856-869. [CrossRef]

10. Miles, J.R.; Vallet, J.L.; Freking, B.A.; Nonneman, D.J. Molecular cloning and characterisation of heparanase mRNA in the porcine placenta throughout gestation. Reprod. Fertil. Dev. 2009, 21, 757-772. [CrossRef]

11. Han, K.; Ren, R.; Cao, J.; Zhao, S.; Yu, M. Genome-Wide Identification of Histone Modifications Involved in Placental Development in Pigs. Front. Genet. 2019, 10, 277. [CrossRef] [PubMed]

12. Gugnoni, M.; Ciarrocchi, A. Long Noncoding RNA and Epithelial Mesenchymal Transition in Cancer. Int. J. Mol. Sci. 2019, 20, 1924. [CrossRef] [PubMed]

13. Kung, J.T.; Colognori, D.; Lee, J.T. Long noncoding RNAs: Past, present, and future. Genetics 2013, 193, 651-669. [CrossRef] [PubMed]

14. Fang, Y.; Fullwood, M.J. Roles, Functions, and Mechanisms of Long Non-coding RNAs in Cancer. Genom. Proteom. Bioinf. 2016, 14, 42-54. [CrossRef] [PubMed]

15. Ma, L.; Deng, C. Identification of a novel four-lncRNA signature as a prognostic indicator in cirrhotic hepatocellular carcinoma. PeerJ 2019, 7, e7413. [CrossRef]

16. Ma, L.; Bajic, V.B.; Zhang, Z. On the classification of long non-coding RNAs. RNA Biol. 2013, 10, 925-933. [CrossRef]

17. Penny, G.D.; Kay, G.F.; Sheardown, S.A.; Rastan, S.; Brockdorff, N. Requirement for Xist in X chromosome inactivation. Nature 1996, 379, 131-137. [CrossRef]

18. Mercer, T.R.; Dinger, M.E.; Mattick, J.S. Long non-coding RNAs: Insights into functions. Nat. Rev. Genet. 2009, 10, 155-159. [CrossRef]

19. Bartolomei, M.S.; Zemel, S.; Tilghman, S.M. Parental Imprinting of the Mouse H19 Gene. Nature 1991, 351, 153-155. [CrossRef]

20. Majewska, M.; Lipka, A.; Paukszto, L.; Jastrzebski, J.P.; Gowkielewicz, M.; Jozwik, M.; Majewski, M.K. Preliminary RNA-Seq Analysis of Long Non-Coding RNAs Expressed in Human Term Placenta. Int. J. Mol. Sci. 2018, 19, 1894. [CrossRef]

21. Basak, T.; Ain, R. Long non-coding RNAs in placental development and disease. Non-Coding RNA Investig. 2019, 3, 14. [CrossRef]

22. Apicella, C.; Ruano, C.S.M.; Mehats, C.; Miralles, F.; Vaiman, D. The Role of Epigenetics in Placental Development and the Etiology of Preeclampsia. Int. J. Mol. Sci. 2019, 20, 2837. [CrossRef]

23. He, X.; He, Y.; Xi, B.; Zheng, J.; Zeng, X.; Cai, Q.; Ouyang, Y.; Wang, C.; Zhou, X.; Huang, H.; et al. LncRNAs expression in preeclampsia placenta reveals the potential role of LncRNAs contributing to preeclampsia pathogenesis. PLoS ONE 2013, 8, e81437. [CrossRef]

24. Troy, A.; Sharpless, N.E. Genetic "lnc"-age of noncoding RNAs to human disease. J. Clin. Investig. 2012, 122, 3837-3840. [CrossRef] [PubMed]

25. Bischoff, S.R.; Tsai, S.Q.; Hardison, N.E.; Motsinger-Reif, A.A.; Freking, B.A.; Nonneman, D.J.; Rohrer, G.A.; Piedrahita, J.A. Differences in X-chromosome transcriptional activity and cholesterol metabolism between placentae from swine breeds from Asian and Western origins. PLoS ONE 2013, 8, e55345. [CrossRef] [PubMed] 
26. Turner, B.M. Epigenetic responses to environmental change and their evolutionary implications. Philos Trans. R. Soc. B 2009, 364, 3403-3418. [CrossRef]

27. Karlić, R.; Chung, H.-R.; Lasserre, J.; Vlahoviček, K.; Vingron, M. Histone modification levels are predictive for gene expression. Proc. Natl. Acad. Sci. USA 2010, 107, 2926-2931. [CrossRef]

28. Heintzman, N.D.; Hon, G.C.; Hawkins, R.D.; Kheradpour, P.; Stark, A.; Harp, L.F.; Ye, Z.; Lee, L.K.; Stuart, R.K.; Ching, C.W.; et al. Histone modifications at human enhancers reflect global cell-type-specific gene expression. Nature 2009, 459, 108-112. [CrossRef]

29. Wan, G.; Zhou, W.; Hu, Y.; Ma, R.; Jin, S.; Liu, G.; Jiang, Q. Transcriptional Regulation of lncRNA Genes by Histone Modification in Alzheimer's Disease. BioMed Res. Int. 2016, 2016, 3164238. [CrossRef]

30. Yang, Y.W.; Flynn, R.A.; Chen, Y.; Qu, K.; Wan, B.; Wang, K.C.; Lei, M.; Chang, H.Y. Essential role of IncRNA binding for WDR5 maintenance of active chromatin and embryonic stem cell pluripotency. eLife 2014, 3, e02046. [CrossRef]

31. Lu, W.; Yu, J.; Shi, F.; Zhang, J.; Huang, R.; Yin, S.; Songyang, Z.; Huang, J. The long non-coding RNA Snhg3 is essential for mouse embryonic stem cell self-renewal and pluripotency. Stem Cell Res. Ther. 2019, 10, 157. [CrossRef]

32. Kim, D.; Langmead, B.; Salzberg, S.L. HISAT: A fast spliced aligner with low memory requirements. Nat. Methods 2015, 12, 357-360. [CrossRef]

33. Trapnell, C.; Williams, B.A.; Pertea, G.; Mortazavi, A.; Kwan, G.; van Baren, M.J.; Salzberg, S.L.; Wold, B.J.; Pachter, L. Transcript assembly and quantification by RNA-Seq reveals unannotated transcripts and isoform switching during cell differentiation. Nat. Biotechnol. 2010, 28, 511-515. [CrossRef] [PubMed]

34. Pertea, M.; Pertea, G.M.; Antonescu, C.M.; Chang, T.-C.; Mendell, J.T.; Salzberg, S.L. StringTie enables improved reconstruction of a transcriptome from RNA-seq reads. Nat. Biotechnol. 2015, 33, 290-295. [CrossRef]

35. Pertea, M.; Kim, D.; Pertea, G.M.; Leek, J.T.; Salzberg, S.L. Transcript-level expression analysis of RNA-seq experiments with HISAT, StringTie and Ballgown. Nat. Protoc. 2016, 11, 1650-1667. [CrossRef]

36. Kong, L.; Zhang, Y.; Ye, Z.-Q.; Liu, X.-Q.; Zhao, S.-Q.; Wei, L.; Gao, G. CPC: Assess the protein-coding potential of transcripts using sequence features and support vector machine. Nucleic Acids Res. 2007, 35, W345-W349. [CrossRef]

37. Wang, L.; Park, H.J.; Dasari, S.; Wang, S.; Kocher, J.-P.; Li, W. CPAT: Coding-Potential Assessment Tool using an alignment-free logistic regression model. Nucleic Acids Res. 2013, 41, e74. [CrossRef] [PubMed]

38. Robinson, M.D.; McCarthy, D.J.; Smyth, G.K. edgeR: A Bioconductor package for differential expression analysis of digital gene expression data. Bioinformatics 2009, 26, 139-140. [CrossRef] [PubMed]

39. Vandesompele, J.; De Preter, K.; Pattyn, F.; Poppe, B.; Roy, N.; De Paepe, A. Accurate normalization of real-time quantitative RT-PCR data by geometric averaging of multiple internal control genes. Genome Biol. 2002, 3, 1-11. [CrossRef]

40. Biensen, N.J.; Wilson, M.E.; Ford, S.P. The impact of either a Meishan or Yorkshire uterus on Meishan or Yorkshire fetal and placental development to days 70, 90, and 110 of gestation2. J. Anim. Sci. 1998, 76, 2169-2176. [CrossRef]

41. Czaja, E.; Wieciech-Rojkiewicz, I.; Knapczyk-Stwora, K.; Grzesiak, M.; Slomczynska, M. The impact of antiandrogen flutamide on the hypoxia inducible factor $1 \mathrm{a}$ and vascular endothelial growth factor a gene and protein expression in the pig placenta during late pregnancy. Folia Histochem. Cytobiol. 2017, 55, 159-167. [CrossRef] [PubMed]

42. Su, L.; Liu, R.; Cheng, W.; Zhu, M.; Li, X.; Zhao, S.; Yu, M. Expression patterns of microRNAs in porcine endometrium and their potential roles in embryo implantation and placentation. PLoS ONE 2014, 9, e87867. [CrossRef] [PubMed]

43. Liu, R.; Wang, M.; Su, L.; Li, X.; Zhao, S.; Yu, M. The Expression Pattern of MicroRNAs and the Associated Pathways Involved in the Development of Porcine Placental Folds That Contribute to the Expansion of the Exchange Surface Area. Biol. Reprod. 2015, 93, 62. [CrossRef] [PubMed]

44. Wang, P.; Song, Y.; Zhong, H.; Lin, S.; Zhang, X.; Li, J.; Che, L.; Feng, B.; Lin, Y.; Xu, S.; et al. Transcriptome Profiling of Placenta through Pregnancy Reveals Dysregulation of Bile Acids Transport and Detoxification Function. Int. J. Mol. Sci. 2019, 20, 4099. [CrossRef] 
45. Hong, L.; Han, K.; Wu, K.; Liu, R.; Huang, J.; Lunney, J.K.; Zhao, S.; Yu, M. E-cadherin and ZEB2 modulate trophoblast cell differentiation during placental development in pigs. Reproduction 2017, 154, 765-775. [CrossRef]

46. Vallet, J.L.; Miles, J.R.; Freking, B.A. Effect of fetal size on fetal placental hyaluronan and hyaluronoglucosaminidases throughout gestation in the pig. Anim. Reprod. Sci. 2010, 118, 297-309. [CrossRef]

47. Zhang, H.; Huang, Y.; Wang, L.; Yu, T.; Wang, Z.; Chang, L.; Zhao, X.; Luo, X.; Zhang, L.; Tong, D. Immortalization of porcine placental trophoblast cells through reconstitution of telomerase activity. Theriogenology 2016, 85, 1446-1456. [CrossRef]

48. Friess, A.E.; Sinowatz, F.; Skolek-Winnisch, R.; Träutner, W. The placenta of the pig. Anat. Embryol. 1980, 158, 179-191. [CrossRef]

49. Gauster, M.; Huppertz, B. Letter from the guest editors: Cell adhesion, migration, and fusion in placenta. Cell Adhes. Migr. 2016, 10, 1. [CrossRef]

50. Chen, D.-B.; Zheng, J. Regulation of Placental Angiogenesis. Microcirculation 2014, 21, 15-25. [CrossRef]

51. Wu, S.C.; Kallin, E.M.; Zhang, Y. Role of H3K27 methylation in the regulation of lncRNA expression. Cell Res. 2010, 20, 1109-1116. [CrossRef] [PubMed]

52. Wu, Z.; Liu, X.; Liu, L.; Deng, H.; Zhang, J.; Xu, Q.; Cen, B.; Ji, A. Regulation of lncRNA expression. Cell. Mol. Biol. Lett. 2014, 19, 561-575. [CrossRef] [PubMed]

53. Ruan, D.; Peng, J.; Wang, X.; Ouyang, Z.; Zou, Q.; Yang, Y.; Chen, F.; Ge, W.; Wu, H.; Liu, Z.; et al. XIST Derepression in Active X Chromosome Hinders Pig Somatic Cell Nuclear Transfer. Stem Cell Rep. 2018, 10, 494-508. [CrossRef] [PubMed]

54. Barski, A.; Cuddapah, S.; Cui, K.; Roh, T.-Y.; Schones, D.E.; Wang, Z.; Wei, G.; Chepelev, I.; Zhao, K. High-Resolution Profiling of Histone Methylations in the Human Genome. Cell 2007, 129, 823-837. [CrossRef] [PubMed]

55. Wang, Z.; Zang, C.; Rosenfeld, J.A.; Schones, D.E.; Barski, A.; Cuddapah, S.; Cui, K.; Roh, T.-Y.; Peng, W.; Zhang, M.Q.; et al. Combinatorial patterns of histone acetylations and methylations in the human genome. Nat. Genet. 2008, 40, 897-903. [CrossRef] [PubMed]

56. Creyghton, M.P.; Cheng, A.W.; Welstead, G.G.; Kooistra, T.; Carey, B.W.; Steine, E.J.; Hanna, J.; Lodato, M.A.; Frampton, G.M.; Sharp, P.A.; et al. Histone H3K27ac separates active from poised enhancers and predicts developmental state. Proc. Natl. Acad. Sci. 2010, 107, 21931. [CrossRef]

57. Zhao, L.; Wang, S.; Cao, Z.; Ouyang, W.; Zhang, Q.; Xie, L.; Zheng, R.; Guo, M.; Ma, M.; Hu, Z.; et al. Chromatin loops associated with active genes and heterochromatin shape rice genome architecture for transcriptional regulation. Nat. Commun. 2019, 10, 3640. [CrossRef]

58. Ferrari, K.J.; Scelfo, A.; Jammula, S.; Cuomo, A.; Barozzi, I.; Stützer, A.; Fischle, W.; Bonaldi, T.; Pasini, D. Polycomb-Dependent H3K27me1 and H3K27me2 Regulate Active Transcription and Enhancer Fidelity. Mol. Cell 2014, 53, 49-62. [CrossRef]

59. Song, G.; Bailey, D.W.; Dunlap, K.A.; Burghardt, R.C.; Spencer, T.E.; Bazer, F.W.; Johnson, G.A. Cathepsin B, Cathepsin L, and Cystatin C in the Porcine Uterus and Placenta: Potential Roles in Endometrial/Placental Remodeling and in Fluid-Phase Transport of Proteins Secreted by Uterine Epithelia Across Placental Areolae. Biol. Reprod. 2010, 82, 811, 854-864. [CrossRef]

60. Varanou, A.; Withington, S.L.; Lakasing, L.; Williamson, C.; Burton, G.J.; Hemberger, M. The importance of cysteine cathepsin proteases for placental development. J. Mol. Med. 2006, 84, 305-317. [CrossRef]

61. Li, Y.; Lopez, G.E.; Vazquez, J.; Sun, Y.; Chavarria, M.; Lindner, P.N.; Fredrickson, S.; Karst, N.; Stanic, A.K. Decidual-Placental Immune Landscape During Syngeneic Murine Pregnancy. Front. Immunol. $2018,9$. [CrossRef] [PubMed]

62. Behjati, S.; Tarpey, P.S.; Sheldon, H.; Martincorena, I.; Van Loo, P.; Gundem, G.; Wedge, D.C.; Ramakrishna, M.; Cooke, S.L.; Pillay, N.; et al. Recurrent PTPRB and PLCG1 mutations in angiosarcoma. Nat. Genet. 2014, 46, 376-379. [CrossRef]

63. Liby, T.A.; Spyropoulos, P.; Buff Lindner, H.; Eldridge, J.; Beeson, C.; Hsu, T.; Muise-Helmericks, R.C. Akt3 controls vascular endothelial growth factor secretion and angiogenesis in ovarian cancer cells. Int. J. Cancer 2012, 130, 532-543. [CrossRef] [PubMed] 
64. Haslinger, P.; Haider, S.; Sonderegger, S.; Otten, J.V.; Pollheimer, J.; Whitley, G.; Knöfler, M. AKT Isoforms 1 and 3 Regulate Basal and Epidermal Growth Factor-Stimulated SGHPL-5 Trophoblast Cell Migration in Humans1. Biol. Reprod. 2013, 88. [CrossRef] [PubMed]

65. Davies, J.; Pollheimer, J.; Yong, H.E.J.; Kokkinos, M.I.; Kalionis, B.; Knöfler, M.; Murthi, P. Epithelialmesenchymal transition during extravillous trophoblast differentiation. Cell Adhes. Migr. 2016, 10, 310-321. [CrossRef] [PubMed]

66. Gordon, K.J.; Blobe, G.C. Role of transforming growth factor- $\beta$ superfamily signaling pathways in human disease. Biochim. Biophys. Acta Mol. Basis Dis. 2008, 1782, 197-228. [CrossRef]

67. Clark, D.E.; Smith, S.K.; Sharkey, A.M.; Charnock-Jones, D.S. Localization of VEGF and expression of its receptors flit and KDR in human placenta throughout pregnancy. Hum. Reprod. 1996, 11, 1090-1098. [CrossRef]

68. Winther, H.; Ahmed, A.; Dantzer, V. Immunohistochemical Localization of Vascular Endothelial Growth Factor (VEGF) and its Two Specific Receptors, Flt-1 and KDR, in the Porcine Placenta and Non-pregnant Uterus. Placenta 1999, 20, 35-43. [CrossRef]

69. Brown, E.J.; Frazier, W.A. Integrin-associated protein (CD47) and its ligands. Trends Cell Biol. 2001, 11, 130-135. [CrossRef]

70. Kaur, S.; Chang, T.; Singh, S.P.; Lim, L.; Mannan, P.; Garfield, S.H.; Pendrak, M.L.; Soto-Pantoja, D.R.; Rosenberg, A.Z.; Jin, S.; et al. CD47 Signaling Regulates the Immunosuppressive Activity of VEGF in T Cells. J. Immunol. 2014, 193, 3914. [CrossRef] [PubMed]

71. Feng, L.; Liao, W.X.; Luo, Q.; Zhang, H.H.; Wang, W.; Zheng, J.; Chen, D.B. Caveolin-1 orchestrates fibroblast growth factor 2 signaling control of angiogenesis in placental artery endothelial cell caveolae. J. Cell Physiol. 2012, 227, 2480-2491. [CrossRef] [PubMed]

72. Bauer, P.M.; Yu, J.; Chen, Y.; Hickey, R.; Bernatchez, P.N.; Looft-Wilson, R.; Huang, Y.; Giordano, F.; Stan, R.V.; Sessa, W.C. Endothelial-specific expression of caveolin-1 impairs microvascular permeability and angiogenesis. Proc. Natl. Acad. Sci. USA 2005, 102, 204. [CrossRef]

73. Tahir, S.A.; Park, S.; Thompson, T.C. Caveolin-1 regulates VEGF-stimulated angiogenic activities in prostate cancer and endothelial cells. Cancer Biol. Ther. 2009, 8, 2284-2294. [CrossRef] [PubMed]

74. Liu, R.; Deng, D.; Liu, X.; Xiao, Y.; Huang, J.; Wang, F.; Li, X.; Yu, M. A miR-18a binding-site polymorphism in CDC42 3'UTR affects CDC42 mRNA expression in placentas and is associated with litter size in pigs. Mamm. Genome 2018, 30, 34-41. [CrossRef] [PubMed]

75. Chang, W.-L.; Liu, Y.-W.; Dang, Y.-L.; Jiang, X.-X.; Xu, H.; Huang, X.; Wang, Y.-L.; Wang, H.; Zhu, C.; Xue, L.-Q.; et al. PLAC8, a new marker for human interstitial extravillous trophoblast cells, promotes their invasion and migration. Development 2018, 145, dev148932. [CrossRef]

76. Rooney, C.; White, G.; Nazgiewicz, A.; Woodcock, S.A.; Anderson, K.I.; Ballestrem, C.; Malliri, A. The Rac activator STEF (Tiam2) regulates cell migration by microtubule-mediated focal adhesion disassembly. EMBO Rep. 2010, 11, 292-298. [CrossRef]

77. Chen, J.-S.; Su, I.-J.; Leu, Y.-W.; Young, K.-C.; Sun, H.S. Expression of T-cell lymphoma invasion and metastasis 2 (TIAM2) promotes proliferation and invasion of liver cancer. Int. J. Cancer 2012, 130, 1302-1313. [CrossRef] [PubMed]

78. Engreitz, J.M.; Haines, J.E.; Perez, E.M.; Munson, G.; Chen, J.; Kane, M.; McDonel, P.E.; Guttman, M.; Lander, E.S. Local regulation of gene expression by lncRNA promoters, transcription and splicing. Nature 2016, 539, 452-455. [CrossRef]

79. Gil, N.; Ulitsky, I. Regulation of gene expression by cis-acting long non-coding RNAs. Nat. Rev. Genet. 2020, 21, 102-117. [CrossRef]

80. Engreitz, J.M.; Pandya-Jones, A.; McDonel, P.; Shishkin, A.; Sirokman, K.; Surka, C.; Kadri, S.; Xing, J.; Goren, A.; Lander, E.S.; et al. The Xist lncRNA Exploits Three-Dimensional Genome Architecture to Spread Across the $X$ Chromosome. Science 2013, 341, 1237973. [CrossRef]

81. Zhao, W.; Mu, Y.; Ma, L.; Wang, C.; Tang, Z.; Yang, S.; Zhou, R.; Hu, X.; Li, M.H.; Li, K. Systematic identification and characterization of long intergenic non-coding RNAs in fetal porcine skeletal muscle development. Sci. Rep. 2015, 5, 8957. [CrossRef] [PubMed]

(C) 2020 by the authors. Licensee MDPI, Basel, Switzerland. This article is an open access article distributed under the terms and conditions of the Creative Commons Attribution (CC BY) license (http://creativecommons.org/licenses/by/4.0/). 